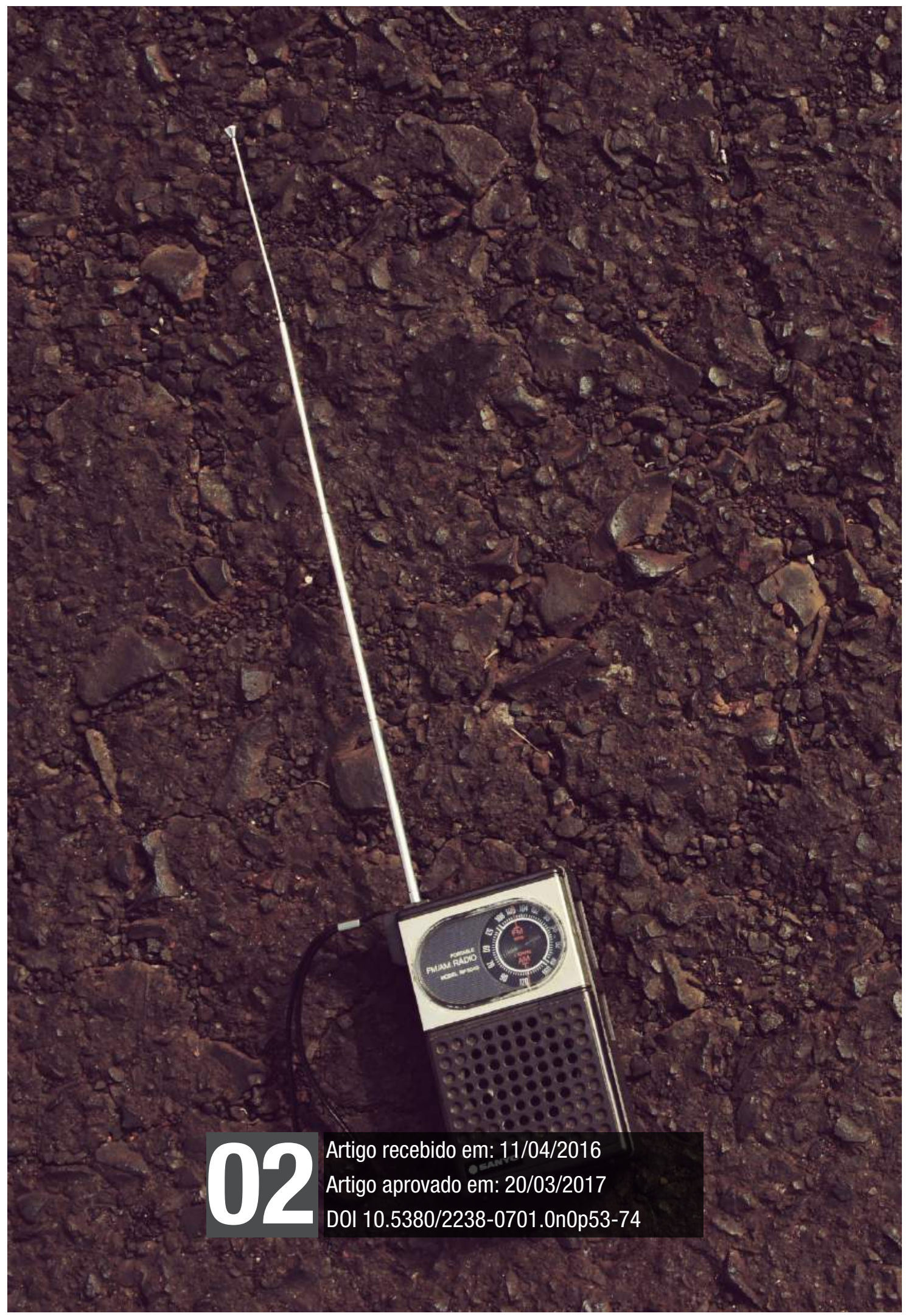


Rádio comunitária. Desenvolvimento sociopolítico local. Poder popular.

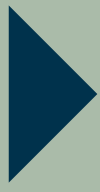




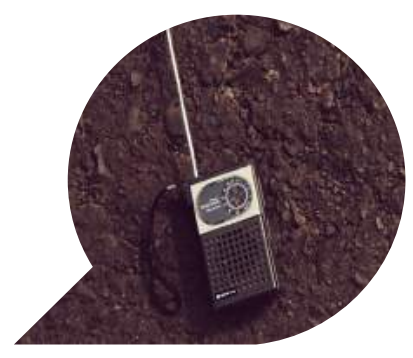

\section{O papel das rádios comunitárias no contexto de desenvolvimento sociopolítico local no Paraná}

\section{The role of community radio in the context of local sociopolitical development in Paraná}

\author{
El papel de la radio comunitaria en el contexto \\ del desarrollo sociopolítico local en Paraná
}

Resumo: Em especial, na última década, as rádios comunitárias têm desempenhado um papel estratégico de fundamental importância nos processos de desenvolvimento e fortalecimento sociopolítico das comunidades e das organizações sociais locais, apesar dos desvios e equívocos políticos que, sabidamente, algumas dessas emissoras têm cometido em suas práticas. No estado do Paraná são mais de duas centenas de rádios comunitárias com concessão e em plena atividade, e outras dezenas aguardando licença para funcionamento, potencializando a atuação comunitária e ampliando as formas de participação e poder popular. Nesse sentido, o objetivo deste artigo é verificar a presença das

\footnotetext{
${ }^{1}$ Graduaçã̃o em Jornalismo e História. Mestrado em Comunicação pela ECA/USP. Doutorado em História pela Unesp/Campus Assis. Pós-doutorado pela ECA/USP. Professor do Departamento de Comunicação da Universidade Estadual de Londrina (UEL). Vice Coordenador do Programa de Mestrado em Comunicação da UEL. Coordenador do Núcleo de Pesquisa em Comunicação Popular (CNPq). E-mail: mianirozinaldo@gmail.com
} 
rádios comunitárias no referido estado, bem como refletir sobre a importância da atuação dessas emissoras de rádio na perspectiva do desenvolvimento sociopolítico local e da construção do poder popular.

Palavras-chave: Rádio comunitária; Desenvolviwwmento sociopolítico local; Poder popular; Participação; Paraná.

Abstract: Especially in the last decade, community radios have played a strategic role of fundamental importance in the processes of sociopolitical development and strengthening of communities and local social organizations, in spite of misunderstandings and deviations politicians who are known to have committed some of these stations in their practices. In the state of Paraná, are more than two hundred community radio stations with grant and in full swing, and dozens awaiting license for operation, strengthening community action and expanding the forms of participation and popular power, this is understood as the set of experiments mobilization and struggle, forged from the immediate needs of the population. In this sense, the purpose of this article is to verify the presence of community radio stations in that state, as well as reflect on the importance of the work of these radio stations in the local sociopolitical development perspective and the construction of popular power.

Keywords: Community radio; Local sociopolitical development; Popular power; Participation; Paraná.

Resumen: En especial, en la última década, las estaciones de radio comunitarias han desempeñado un papel estratégico de importancia fundamental en los procesos de desarrollo y fortalecimiento sociopolítico de las comunidades locales y las organizaciones sociales, a pesar de las desviaciones y las ideas erróneas políticas que, como son conocidas, algunas de estas estaciones se han comprometido en sus prácticas. En el estado de Paraná, son más de doscientas concesiónes de radio comunitaria y en pleno desarrollo, y otras más a la espera de la licencia para la operación, potenciadoras del fortalecimiento de la acción comunitaria y la expansión de las formas de participación y poder popular. En este sentido, el propósito de este artículo es examinar las estaciones de radio comunitarias en ese estado, así como reflexionar sobre las ideas, aportes, desafíos y limitaciones en los procesos de organización y las actividades de estas es- 
taciones de radio en la perspectiva del desarrollo local y sociopolítico $y$ de la construcción del poder popular.

Palabras clave: Radio comunitaria; Desarrollo sociopolítico local; Poder popular; Participación; Paraná. 


\section{Introdução}

Os processos de organização política local e mobilização comunitária têm se fortalecido ao longo dos últimos anos, principalmente por meio da implantação de rádios comunitárias nos mais diversos municípios brasileiros. Ao todo são mais de 4.700 processos em andamento, registrados no Ministério das Comunicações ${ }^{2}$, espalhados por todas as regiões do país.

Na região sul, essa realidade atinge uma significativa parcela das cidades e promove a consolidação de um importante instrumento de desenvolvimento territorial e local. No Rio Grande do Sul, dos $496 \mathrm{mu}$ nicípios do estado, 353 deles contam com a presença de rádios comunitárias, totalizando $71,2 \%$ de municípios atendidos por esse serviço de comunicação, com destaque para a cidade de Pelotas que tem 10 processos de solicitação para funcionamento de rádios comunitárias; no total são 413 emissoras de rádio comunitária atuando no estado. Em Santa Catarina são 197 de 293 municípios que contam com o serviço de radiodifusão comunitária, atingindo $67,2 \%$ das cidades do estado; ao todo são 219 rádios operando nas cidades catarinenses.

No estado do Paraná que, em particular, nos interessa para este trabalho, são 322 emissoras de rádio comunitária registradas junto ao Ministério das Comunicações, atuando em 294 dos 399 municípios do estado. Esse número equivale a $73,7 \%$ das cidades paranaenses (o maior índice entre os estados da região sul) que, assim, contam com o serviço de radiodifusão comunitária. Ainda a esse respeito, vale destacar que são 277 municípios com apenas uma emissora; 12 cidades que contam com duas emissoras em atividade (Antonina, Campina Grande do Sul, Cianorte, Fazenda Rio Grande, Foz do Iguaçu, Francisco Beltrão, Nova Laranjeiras, Paranaguá, Paranavaí, Pinhais, Rolândia e Umuarama); Londrina, Maringá e Cascavel que contam com três emissoras em cada uma das referidas cidades; Campo Largo, com a presença de quatro emissoras; e Curitiba, a capital do estado, que possui oito autorizações para operar emissoras de rádio comunitária.

Das 322 rádios comunitárias no estado do Paraná, 34 delas encontram-se em débito com a Anatel e, por isso, as entidades requerentes estão impossibilitadas de receberem a licença para operação de radiodifusão. No entanto, a grande maioria delas, no total de 223, já possui a

\footnotetext{
${ }^{2}$ Os dados apresentados neste artigo foram obtidos junto ao site do Ministério das Comunicações, atualizado em março de 2016. Disponível em: http://www.comunicacoes.gov.br/formularios-e-requerimentos/doc_download/2796-entidades-autorizadas-arquivo-pdf
} 
licença definitiva para operar e 11 obtiveram a renovação de sua licença definitiva. Ainda em relação à situação de licença definitiva, dez entidades aguardam as providências para o recebimento de tal licença e outras cinco esperam apenas a assinatura do ministro. Com relação às emissoras de rádio comunitária que operam com licença provisória, 16 delas estão em operação com a referida licença já recebida pelas entidades e duas aguardam a assinatura do ministro.

O estado do Paraná ainda conta com 14 processos de rádios comunitárias em que a entidade requerente recebeu a autorização para executar o serviço de radiodifusão comunitária por meio de Portaria Ministerial, e outras sete emissoras, cuja autorização ministerial foi deliberada pelo Congresso Nacional por meio de Decreto Legislativo.

Diante de tal realidade, esse artigo pretende apresentar algumas questões e problematizações preliminares acerca da importância, dos desafios e dos limites da presença das rádios comunitárias como estratégia de desenvolvimento e fortalecimento sociopolítico das comunidades e das organizações sociais locais, tendo como pano de fundo a expressiva presença de rádios comunitárias nos municípios paranaenses.

Faremos, inicialmente, uma breve contextualização sobre a realidade social e política das rádios comunitárias no Brasil e, em seguida, uma discussão sobre o conceito de desenvolvimento sociopolítico local e poder popular. Por fim, apresentaremos algumas questões relacionadas aos processos de organização e atuação das rádios comunitárias no Paraná e suas potencialidades políticas no contexto do processo de disputa de hegemonias.

\section{A consolidação das rádios comunitárias no Brasil}

A luta política no Brasil pela democratização da comunicação, de modo geral, e pela apropriação social da radiodifusão como estratégia de organização e mobilização popular, antecede a aprovação da lei de radiodifusão comunitária (Lei no 9.612 de 1998).

Várias experiências de rádio comunitária foram registradas no Brasil durante a segunda metade do século $\mathrm{XX}^{3}$, porém o movimento mais significativo de iniciativas de apropriação da radiodifusão para processos políticos de organização e mobilização popular data do início da década de 1980, com a experiência das rádios livres. Segundo Cicília

\footnotetext{
${ }^{3}$ Nessa história, cabe também incluir algumas rádios piratas e as rádios livres que, apesar de terem configurações e características diferentes entre si, devem ser consideradas como pertencentes a uma mesma "linhagem" de experiências radiofônicas de natureza alternativa e/ou contra-hegemônica.
} 
Peruzzo,

As rádios livres, mesmo que algumas possam ter sido decorrência de aventuras sem maiores pretensões políticas, são, no conjunto, um protesto contra a forma de acesso aos instrumentos massivos e uma tentativa de conquistar a liberdade de expressão a qualquer preço. Elas contribuíram para o debate sobre a estrutura dos meios de comunicação no Brasil (PERUZZO, 1998, p. 245).

Em relação ao contexto e às reivindicações da época que impulsionaram o movimento das rádios livres, Arlindo Machado, Caio Magri e Marcelo Mazagão afirmam que

À exceção das poucas emissoras estatais, os meios de radiodifusão são hoje mantidos basicamente por grupos de interesses comerciais, que deles se utilizam para vender mercadorias e multiplicar o capital. Até aí, tudo muito natural, visto vivermos sob um regime capitalista, para cuja reprodução as mídias são fatores imprescindíveis. Mas deve haver espaço também para outras modalidades de exploração, mais democráticas e que permitam engajar a iniciativa da própria comunidade atingida pelos meios. Nesse espaço alternativo podem caber, por exemplo, emissoras ligadas a grupos de produção cultural, a grupos de intervenção social, às minorias étnicas, culturais ou sexuais, aos partidos políticos, às comunidades locais e também aos amantes do rádio e da TV para aí realizarem experiências renovadoras de linguagem. O leque de opções, enfim, deve ser tão amplo quanto a diversidade dos cidadãos (MACHADO; MAGRI; MAZAGÃO, 1986, p. 17-18).

O fortalecimento das organizações e grupos populares que atuavam na perspectiva de utilização da radiodifusão para suas práticas políticas, sociais ou culturais (e aqui já merecem destaque os grupos que passaram a se identificar com a expressão "rádio comunitária") foi uma das principais condições para a criação de um movimento social pela democratização da comunicação: tratava-se da Frente Nacional pela Democratização na Comunicação (FNDC), que foi um movimento muito atuante durante o processo da Assembleia Nacional Constituinte, garantindo, inclusive, uma redação no texto da Constituição de 1988, que prevê, em linhas gerais, que "o povo brasileiro tem o direito de ter e gerir um sistema público não-estatal de informação, comunicação e cultura" (GIRARDI; JACOBUS, 2009, p. 21).

Desde então os militantes, os ativistas e os simpatizantes de rádios comunitárias se articularam em várias organizações, com o objetivo de 
garantir a elaboração de uma legislação que pudesse atender ao direito constitucional do acesso, da produção e da gestão de emissoras de radiodifusão.

Depois de muita pressão e mobilização popular, o governo de Fernando Henrique Cardoso (1995-2002) acabou aprovando uma lei tratando da referida questão. Apesar de ser uma reivindicação antiga das organizações populares atuantes na questão da democratização da comunicação e do direito ao acesso à radiodifusão, o que a Lei 9.612/98 (datada de 19 de fevereiro de 1998) ofereceu ficou muito aquém daquilo que se desejava, caracterizando muito mais uma "armadilha" contra as rádios comunitárias do que propriamente uma conquista. Essa também é a opinião, dentre outros pesquisadores do assunto, de Cristiane Dias Andriotti ao afirmar, por ocasião de um estudo sobre o movimento das rádios livres e comunitárias, que

Do ponto de vista técnico, a lei vinha em conformidade com as reivindicações dos empresários de comunicação. [...] O balanço final da Lei das Rádios Comunitárias acabou sendo negativo. Todas as contradições entre as especificações da lei, os interesses do movimento, os interesses dos empresários de comunicação, a própria natureza física, geraram complicados debates políticos dentro do movimento, além de protestos por todo o país na forma de mais intervenções de rádios ilegais dentro do espectro (ANDRIOTTI, 2004, p. 139/143).

Dentre os entraves provocados pela lei estão: a excessiva burocracia para a obtenção da concessão para funcionamento de uma rádio comunitária, a limitação do alcance do sinal da emissora de rádio (que não pode ultrapassar o raio de um quilômetro), a proibição de inserção de propaganda comercial, exceto sob a forma de apoio cultural, inviabilizando o financiamento de muitas emissoras comunitárias e o impedimento de formação de redes para a produção radiofônica, promovendo o completo isolamento das rádios comunitárias. Diante desse quadro, Dioclécio Luz assim resumiu a questão: "Quando o movimento das rádios comunitárias buscou a regulamentação, o latifúndio [das comunicações], através dos seus porta-vozes no Congresso Nacional, estabeleceu a lei 9.612/98, que é inaceitável para o povo brasileiro" (LUZ, 2007, p. 42).

Apesar disso, após a referida lei - mesmo que ela não tivesse atendido aos interesses mais legítimos dos grupos sociais defensores da democratização da comunicação - houve um crescimento no interesse de 
vários grupos populares e comunitários no sentido de propor a criação de rádios comunitárias, principalmente, com o objetivo de oferecer alternativas comunicacionais às mais diversas e distintas localidades em todos os estados brasileiros.

A necessidade de alterações na lei de radiodifusão comunitária é quase uma unanimidade entre os estudiosos e ativistas de rádio comunitária, mas não podemos ignorar a realidade que se estabeleceu a partir da atual legislação. Como já dissemos, existem mais de 4.700 processos em andamento no Ministério das Comunicações (entre licenças já concedidas e outras em processo de autorização) que configuram uma importante realidade de organização e articulação das rádios comunitárias no Brasil.

A esse respeito é preciso ressalvar que há toda uma disputa política em torno da própria concepção de rádio comunitária, que vai da mera criação de uma emissora de rádio para atender a interesses pessoais até a articulação de um grande movimento popular de radiodifusão comunitária com a perspectiva político-ideológica de fortalecimento sociopolítico das comunidades e de construção do poder popular, em um processo de disputa de hegemonias.

\section{A importância das rádios comunitárias nos processos de desenvolvimento sociopolítico local}

Para apontar algumas questões preliminares a respeito da importância política e do papel estratégico desempenhado pelas rádios comunitárias nos processos de desenvolvimento e fortalecimento sociopolítico das comunidades e das organizações sociais locais no estado do Paraná, é preciso, antes de tudo, apresentar a concepção de desenvolvimento sociopolítico que fundamenta essa reflexão. Tomamos como referência as contribuições de José Amorim de Oliveira Júnior que, subsidiado nas concepções de democracia de Aléxis de Tocqueville, afirma o seguinte:

O desenvolvimento sociopolítico local pode ser entendido a partir de uma analogia entre a ampliação dos processos de democracia, por meio do governo civil, e os incrementos nos números de redes sociais, de organizações voluntárias da sociedade civil e outras formas de sociabilidade motivadas por processos de cooperação e associação. Assim, Tocqueville tratou, ao escrever A democracia na América, da questão do desenvolvimento sociopolítico, estabelecendo um nexo conotativo 
entre desenvolvimento, sociedade civil e democracia. $\mathrm{O}$ autor francês teria, então, vislumbrado a relação intrínseca entre desenvolvimento e o modo como a sociedade se estrutura e regula seus conflitos, isto é, a relação entre desenvolvimento e democracia (OLIVEIRA JÚNIOR, 2006, p. 13-14).

Nesse sentido, pensar a questão do desenvolvimento sociopolítico local implica, necessariamente, relacioná-lo ao exercício da democracia. Além disso, Oliveira Júnior também trata da importância dos processos de associação que se estabelecem entre os indivíduos de uma determinada localidade, enquanto uma atividade política, como fator essencial para um desenvolvimento sociopolítico. Afirma o autor:

A atividade política afigura-se, portanto, como meio privilegiado de realização do homem. A "arte da associação" de uma comunidade, sua capacidade para atuar em conjunto, por sua vez, afigura-se, como importante fator na determinação do desenvolvimento sustentável das comunidades que realizam tal capacidade, superando um modelo de desenvolvimento social insustentável, fruto de uma visão utilitarista que reduz a política à perseguição de interesses econômicos e privados (OLIVEIRA JÚNIOR, 2006, p. 14).

A respeito da importância da organização de uma comunidade ${ }^{4}$, Fábio Augusto Mansano (2004) apresenta dois objetivos fundamentais de tais processos organizativos:

A organização da comunidade, então, deve privilegiar ações que inibam o marasmo social e denunciem práticas abusivas das classes dominantes. Nesse sentido, a comunidade pode se organizar de duas formas: para o gerenciamento da estrutura social ou para a mobilização e a pressão popular. A primeira é importante porque transforma a população em vigia dos serviços públicos e é um passo importante no lento processo de conquista de espaço político. A segunda forma é mais complexa e, desde que usufruída por parcela significativa da comunidade, pode conduzir a uma efetiva participação nas esferas de poder (MANSANO, 2004, p. 31-32).

\footnotetext{
${ }^{4} \mathrm{O}$ conceito de comunidade exigiria uma problematização e reflexão aprofundada, conforme Raquel Paiva (1998) e Rozinaldo Miani (2011), porém não é o objetivo desse trabalho; nesse sentido, tomaremos comunidade aqui tão somente como delimitação territorial, localidade.
} 
Portanto, o exercício da democracia e o estabelecimento de processos participativos e organizativos, por meio de associações comunitárias, estão na base do desenvolvimento sociopolítico local e, nesse sentido, as rádios comunitárias acabam representando uma importante estratégia política de organização, ampliação e/ou fortalecimento do referido desenvolvimento.

Para além dessa questão, é preciso afirmar que as rádios comunitárias também são apropriadas pelas organizações populares e comunitárias na perspectiva da construção do poder popular e, aqui, ressaltamos seu caráter estratégico na disputa de hegemonias, bem ao modo do pensamento gramsciano (GRAMSCI, 1995). Não há espaço suficiente nos limites desse artigo para aprofundar o debate em torno do que se entende e se deve compreender a respeito do poder popular. Por isso, optamos apenas por indicar a perspectiva política que assumimos a respeito do poder popular para não correr o risco de pecar por ausência de referencial.

Uma das mais produtivas reflexões acerca do conceito de poder popular foi desenvolvida por Gilmar Mauro. Para o autor, trata-se de um "novo poder", que se constitui a partir da lógica e da dinâmica das classes populares e trabalhadoras em sua ação política e que se propõe a "criar novas formas de relações humanas, novas relações societárias, novas relações políticas". Defende o autor que o poder popular "brota e se realiza com e pelo povo (quanto (sic) classe social) num projeto de construção do socialismo" (MAURO, 2006, p. 26).

Gilmar Mauro ressalta ainda que o poder popular se faz com participação popular, de natureza coletiva, e que este deve zelar pela paciência e generosidade, mas também pela persistência e espírito crítico. Em suas conclusões, Mauro afirma:

Criar o Poder Popular significa construir novas relações cotidianamente nos processos de lutas, nas escolas, nas famílias, nas relações entre militantes, nas estruturas organizativas. Em todos os espaços devemos ir forjando e exercitando os valores e a cultura do poder popular. Os sujeitos não se realizam por uma concessão que lhes é dada. Mas por sua luta, pois através dela é que se conquista o direito e se adquire consciência do mesmo. A consciência do Poder Popular não será imposta de fora e nem de cima para baixo, mas de um processo que se dará a partir da "práxis" inovadora, lutas/reflexão, prática/consciência, erros/ acertos. Na atualidade e, para não cair no idealismo, o Poder Popular, enquanto forma, deverá ser o de uma "democracia popular", uma vez 
que ainda, experimentamos e aprendemos em meio às desigualdades. Se existem desigualdades deve haver democracia, respeitando-se as opiniões e os direitos das minorias (politicamente), e que, ao mesmo tempo, se faça um permanente exercício de construção de hegemonia da classe trabalhadora, o mais horizontal possível. [...] Deverá ser um exercício da democracia solidária, de participação direta e de construção da consciência de classe (MAURO, 2006, p. 26).

Retomemos a questão da importância dos processos de associação para a criação de uma emissora de rádio comunitária, enquanto estratégia de desenvolvimento sociopolítico local e de construção do poder popular. Uma das primeiras e principais exigências para criar uma rádio comunitária é que se constitua uma associação. Essa condição está prevista logo no primeiro artigo da lei de radiodifusão comunitária, como se pode observar no referido texto:

Denomina-se Serviço de Radiodifusão Comunitária a radiodifusão sonora, em frequência modulada, operada em baixa potência e cobertura restrita, outorgada a fundações e associações comunitárias, sem fins lucrativos, com sede na localidade de prestação do serviço (BRASIL, 1998, p. 1).

Considerando o que está previsto na legislação, a associação não pode se limitar a apenas um segmento da sociedade; ela tem que abranger toda a comunidade. Isso visa garantir que a rádio comunitária seja um efetivo instrumento de todo o conjunto da comunidade. Mesmo que existam entidades atuando na localidade, faz-se importante que se organize uma entidade específica para operar a rádio comunitária. A esse respeito, afirma Dioclécio Luz:

Se já existe a associação dos moradores de determinado bairro, ela pode alterar o estatuto, incluindo a operação de uma rádio em suas atividades. O ideal, porém, é criar uma associação própria para rádio comunitária que incorpore os vários segmentos da sociedade. $\mathrm{O}$ caráter comunitário é fundamental. Fará parte dela as outras entidades existentes na localidade - sindicatos, associações, instituições religiosas - e pessoas físicas. Estes administrarão a rádio. Em suma, o essencial [...] é que tenha finalidades e objetivos voltados para toda a comunidade, que seja apartidária, sem fins lucrativos, e que não pretenda alcançar apenas um determinado segmento representativo da comunidade (LUZ, 1998). 
O fato de uma rádio comunitária ser organizada e gerenciada por um coletivo de organizações sociais locais possibilita uma maior integração entre os vários segmentos da comunidade e, consequentemente, um maior diálogo e solidariedade entre suas demandas e reivindicações. $\mathrm{O}$ aprendizado político que esse processo potencializa contribui significativamente na articulação sociopolítica da comunidade. Além disso

A capacidade de mobilização autônoma é uma necessidade na disputa por uma visibilidade que realmente chame a atenção para os problemas da comunidade. [...] Construir uma base participante, formada por comunicadores e ouvintes em torno de uma rádio comunitária, é um bom instrumento para aglutinar pessoas e alavancar a prática de um autêntico poder popular. É um exercício conjunto do poder, seja no papel de mero ouvinte, seja no envolvimento direto com os processos de produção, planejamento e gestão da comunicação (GIRARDI; JACOBUS, 2009, p. 32).

Essa questão apresentada por Ilza Girardi e Rodrigo Jacobus nos remete aos processos de participação popular, que também se apresentam como uma importante estratégia de desenvolvimento sociopolítico local. A participação deve ser permanentemente incentivada, afinal, segundo Rozinaldo Miani e Camila Frazatti Felício, ela deve ser compreendida como

[...] um ato político e um ato educativo. Sua prática num contexto domesticador e economicamente desigual como o brasileiro diz respeito não só à participação política, mas também socioeconômica e cultural, desafio que se impõe aos movimentos sociais e populares concomitantemente aos seus objetivos estratégicos (MIANI; FELÍCIO, 2009, p. 6).

Além das questões já apresentadas, faz-se importante ressaltar que, no contexto de uma sociedade globalizada, a existência de uma rádio comunitária em uma determinada localidade permite que sua população tenha um veículo de comunicação específico para dar visibilidade às suas demandas e reivindicações, bem como disseminar sua cultura e suas características peculiares.

As questões apresentadas até agora dão uma dimensão das contribuições que a presença de uma rádio comunitária pode proporcionar às organizações sociais no que se refere ao desenvolvimento sociopolítico local e à construção do poder popular. Porém, esse universo não é só 
marcado por aspectos positivos. Existem desafios e limites que não podem ser negligenciados quando o assunto é rádio comunitária.

Já tratamos dos limites da própria legislação, que não atende aos interesses legítimos dos grupos populares que atuam com a democratização da comunicação. A legislação é restritiva, insuficiente e, em alguns aspectos, adversa aos reais interesses dos militantes e ativistas do movimento das rádios comunitárias, na perspectiva dos processos de disputa de hegemonias. A lei está muito longe de atentar contra os privilégios das grandes corporações midiáticas e de proporcionar uma efetiva democratização da comunicação no Brasil.

Além disso, muitas experiências de rádios comunitárias têm produzido desvios de conduta e mesmo de concepção, em relação ao seu aspecto coletivo e também à sua condição de emissora sem fins lucrativos, não partidária e não religiosa. Muitas emissoras de rádio, que obtiveram a autorização para operar como rádio comunitária, não respeitam a legislação e nem praticam os seus pressupostos políticos. Algumas dessas emissoras sequer contam com a participação da comunidade e outras acabam funcionando aos nos mesmos moldes que as emissoras comerciais, ou seja, com uma programação que não atende aos interesses da população local, ou, ainda, visando a obtenção de lucros para os seus gestores. Não são poucas as emissoras de rádio comunitária que também estão vinculadas (clandestinamente ou não) aos políticos, e outras tantas ligadas às igrejas.

Essa é uma realidade geral que atinge todos os estados brasileiros e que exige de todos aqueles que atuam politicamente junto às rádios comunitárias o desafio de fiscalizar e impedir essas "fraudes", na perspectiva de fortalecer as rádios comunitárias como uma legítima estratégia de organização e mobilização social, com vistas ao desenvolvimento sociopolítico local e construção do poder popular.

Particularmente no estado do Paraná, a questão se apresenta bastante importante, pois, como vimos anteriormente, mais de $73 \%$ dos municípios do estado já contam com pelo menos uma rádio comunitária em atuação. Considerando que o Ministério das Comunicações tem priorizado a autorização de uma única emissora de rádio comunitária nas pequenas cidades, aqueles municípios que já possuem uma rádio comunitária e onde, porventura, tal emissora não esteja cumprindo com o seu papel social e político, as respectivas comunidades perdem a oportunidade de usufruir de um valioso instrumento de organização e mobilização popular. 
Por outro lado, as rádios comunitárias que estão cumprindo bem o seu papel de organizar, mobilizar e articular os mais diversos segmentos da comunidade contribuem para que os respectivos municípios vislumbrem um importante processo de desenvolvimento sociopolítico local, ao possibilitar a participação dos indivíduos na produção e/ou gestão de um veículo de comunicação que trata fundamentalmente de suas demandas e interesses, bem como construindo as bases políticas para a construção de um efetivo poder popular, que possa contribuir no processo de disputa de hegemonias.

\section{As rádios comunitárias no Paraná e o desafio do desenvolvimento sociopolítico local}

O processo de organização e atuação de rádios comunitárias no estado do Paraná é anterior à própria aprovação da lei de radiodifusão comunitária (1998). Porém, a primeira iniciativa para estabelecer uma organização política estadual entre os produtores e ativistas de rádios comunitárias é datada de agosto de 2003, quando foi realizado o I Fórum Estadual de Rádios Comunitárias na cidade de Jataizinho/PR. Em fôlder de apresentação da programação do evento, os objetivos do referido Fórum foram assim descritos:

O I Fórum Estadual de Rádios Comunitárias, em síntese, tem como objetivo principal ativar a ampliar as conexões das rádios comunitárias organizadas, entendidas aqui como expressão das ansiedades, desejos e necessidades de uma coletividade minoritária e excluída da 'sociedade da comunicação', com grupos interessados em articular novas experiências em rádio comunitária [...]. Assim, este Fórum pretende ser um momento de reflexão e ação com o objetivo de oferecer um panorama da situação atual e das tendências da produção radiofônica comunitária no Paraná. Ainda, pretende fortalecer este espaço criado para fazedores de rádio, donos de um ofício cuja responsabilidade cresce frente ao impacto do mundo (I FÓRUM, 2003).

Como um dos desdobramentos desse encontro, que contou com a participação ativa de professores e estudantes da Universidade Estadual de Londrina (UEL), Fábio Augusto Mansano (2004) realizou seu Trabalho de Conclusão de Curso (TCC) em Comunicação Social, com habilitação em Jornalismo, nessa temática. A partir de um questionário 
enviado às rádios comunitárias em atividade à época ${ }^{5}$, o autor apresentou as seguintes constatações:

Em suma, pode-se dizer que a maioria das emissoras comunitárias paranaenses legalizadas possui computadores em seus estúdios, não é filiada a nenhuma associação de rádios comunitárias, precisou de algum apoio político durante a concessão, está situada em cidades que não possuem outros meios de comunicação, não possui outra fonte de renda a não ser a veiculação de apoios culturais na programação, já sofreu algum tipo de perseguição em suas atividades, já recebeu visitas de fiscais da Anatel e não considera a atual legislação adequada para regular esse serviço (MANSANO, 2004, p. 148).

Além dessas constatações, também foi possível verificar que as rádios comunitárias enfrentavam sérias restrições financeiras, principalmente em razão das limitações impostas pela legislação quanto à proibição de recebimento de recursos derivados de propaganda comercial.

Com relação às práticas desenvolvidas pelas emissoras de rádio comunitária paranaenses, Mansano afirmou que a atuaçãode tais organizações estava centrada basicamente em dois interesses: "nas satisfações e participação no nível das mensagens do público atendido e na correspondência das expectativas existentes no grupo responsável pela conquista desses MCC [meios de comunicação comunitários]" (MANSANO, 2004, p. 149). A respeito desse último aspecto, e com a realização de sua pesquisa de campo, o autor constatou inúmeros desvios praticados por rádios comunitárias paranaenses, já descritos e analisados anteriormente, como por exemplo, a personificação, a reprodução do padrão comercial, o proselitismo religioso e a cooptação política partidária. Alguns anos mais tarde, em agosto de 2008, outra iniciativa foi realizada no sentido de consolidar uma organização estadual de rádios comunitárias. Com a presença de representantes da Associação Brasileira de Radiodifusão Comunitária (Abraço) e de apoiadores do movimento

\footnotetext{
${ }^{5}$ Em janeiro de 2004 havia 56 emissoras de rádio comunitária legalizadas no estado do Paraná. Dessas, 40 emissoras foram contatadas para responderem um questionário; 16 delas responderam. Com quatro emissoras foi realizada uma pesquisa de campo - Rádio Nova Geração FM (Jataizinho); Rádio Alternativa FM (Guaratuba); Rádio Milenium FM (Uraí); Rádio São Francisco FM (Maringá). Toda essa pesquisa foi apresentada e analisada por Fábio Augusto Mansano no Trabalho de Conclusão de Curso em Comunicação Social/Jornalismo intitulado "Para uma leitura crítica das rádios comunitárias", no ano de 2004 na Universidade Estadual de Londrina, sob orientação de Rozinaldo Antonio Miani.
} 
de rádios comunitárias ${ }^{6}$, foi realizado na Universidade Estadual de Ponta Grossa (UEPG), o II Encontro Paranaense de Rádios Comunitárias.

Nesse encontro foi constituída uma comissão para organizar o I Congresso Paranaense de Rádios Comunitárias, que seria realizado no dia 08 de novembro de 2008 na Universidade Estadual do Centro-Oeste (Unicentro), cidade de Guarapuava, com o objetivo de discutir e encaminhar a criação de uma Associação ou Federação de Rádios Comunitárias do Paraná. O encontro ocorreu na data prevista e, na ocasião, foi criada a Federação das Mantenedoras de Rádios Comunitárias (Femarcom-PR).

Em clipping produzido à época pelo Fórum Nacional pela Democratização da Comunicação (FNDC), o objetivo da criação da Femarcom-PR foi assim descrito: "A iniciativa visa fortalecer os projetos e ações de produção e difusão em rádio comunitária, numa perspectiva cooperativada, buscando formas de apoio, bem como trocas de experiências e soluções aos problemas atualmente enfrentados pelas emissoras paranaenses" (FNDC, 2008).

Desde então, os desafios enfrentados pelos grupos que atuam com rádios comunitárias no estado do Paraná são tratados de maneira mais coletiva. Diferenças e divergências em relação aos encaminhamentos organizativos e de programação, e mesmo em relação à concepção de rádio comunitária ${ }^{7}$, são constantes, porém é preciso reconhecer que houve um avanço significativo no que se refere à presença e à atuação política das rádios comunitárias no contexto de desenvolvimento sociopolítico local.

Enfim, as rádios comunitárias se constituem como uma importante estratégia política no processo de construção de um poder popular. Fazer desses veículos comunitários um espaço de participação e de exercício da democracia, bem como reconhecê-los como uma arena onde se promovem processos de disputa de hegemonias é uma tarefa urgente para quem deseja e acredita em uma efetiva transformação social.

\footnotetext{
${ }^{6}$ Dentre eles, o Núcleo de Pesquisa em Comunicação Popular (NCP) da Universidade Estadual de Londrina (UEL), a Agência de Jornalismo da Universidade Estadual de Ponta Grossa (UEPG) e o Sindicato dos Jornalistas do Paraná (Sindijor-PR).

${ }^{7}$ Nesse sentido, é necessário reafirmar que os desvios praticados por gestores de rádios comunitárias continuam ocorrendo com frequência e comprometem em muito a credibilidade e, por vezes, a legitimidade dessas emissoras
} 


\section{Considerações finais}

A presença das rádios comunitárias em milhares de municípios brasileiros revela que as organizações populares locais despertaram para a necessidade de construir experiências comunicativas que possam contribuir com a organização e mobilização comunitárias e mesmo para os processos de disputa de hegemonias. Nesse sentido, estamos diante de um importante instrumento de desenvolvimento sociopolítico local e de construção de um poder popular.

Apesar de uma legislação insuficiente, e até mesmo prejudicial em algumas situações, e também não negligenciando os limites e os desvios praticados por grupos não comprometidos com sua respectiva comunidade ou com os princípios ético-políticos para a prática de rádio comunitária, devemos ressaltar a importância estratégica das emissoras de rádios comunitárias para o fortalecimento político das organizações locais.

No Paraná, algumas ações já foram realizadas no sentido de fortalecer uma organização política coletiva e, com isso, favorecendo uma atuação cooperativa entre as rádios comunitárias, consolidando sua condição de estratégia política para o desenvolvimento sociopolítico local.

A realidade das rádios comunitárias é muito dinâmica e ainda há muito para se pesquisar a respeito do tema. Por isso, pretendemos dar seguimento a esses estudos, procurando identificar com maior precisão as contribuições efetivas que cada uma das emissoras de rádio comunitária no estado do Paraná proporciona às suas localidades, bem como avaliar os avanços e/ou retrocessos produzidos pela presença dessas rádios para o desenvolvimento sociopolítico local e para a construção do poder popular.

\section{REFERÊNCIAS}

ANDRIOTTI, Cristiane Dias. O movimento das rádios livres e comunitárias e a democratização dos meios de comunicação no Brasil. Campinas: Unicamp, 2004. Dissertação (Mestrado em Sociologia). Instituto de Filosofia e Ciências Humanas, Universidade Estadual de Campinas, 2004.

BRASIL. Legislação para rádios comunitárias. Brasília, 1998. Disponível em: <http://mc.gov.br/radiodifusão/legislação>. Acesso em: 08 ago. 2011.

COELHO NETO, Armando. Rádio comunitária não é crime, direito de antena: o espectro eletromagnético como bem difuso. São Paulo: Ícone, 2002. 
FNDC. Rádios comunitárias criam federação paranaense. 2008. Disponível em: <http://www.fndc.org.br/clipping/radios-comunitarias-criam-federacaoparanaense-303960/>. Acesso em: 12 nov. 2008.

GIRARDI, Ilza; JACOBUS, Rodrigo. (Org.). Para fazer rádio comunitária com "C" maiúsculo. Porto Alegre: Revolução de Idéias, 2009.

GRAMSCI, Antonio. Concepção dialética da história. 10.ed. Rio de Janeiro: Civilização Brasileira, 1995.

LUZ, Dioclécio. Reforma agrária no ar!: monte uma rádio ou televisão comunitária. 2.ed. Brasília, 1998. Disponível em: <http://www.dhnet.org.br/dados/cartilhas/ciber/br/ radiotv.htm>. Acesso em: 08 fev. 2016.

LUZ, Dioclécio. A arte de pensar e fazer rádios comunitárias. Brasília: [s.n.], 2007.

MACHADO, Arlindo; MAGRI, Caio; MASAGÃO, Marcelo. Rádios livres: a reforma agrária no ar. São Paulo: Brasiliense, 1986.

MANSANO, Fábio Augusto. Para uma leitura crítica das rádios comunitárias. Londrina, UEL, 2004. Trabalho de Conclusão de Curso (Graduação em Comunicação Social/Jornalismo). Centro de Educação, Comunicação e Artes, Universidade Estadual de Londrina, 2004.

MAURO, Gilmar. Construir o poder popular: o grande desafio do novo século. São Paulo, 2006. Disponível em: <http://www.jornallivre.com.br/14950/construir-o-poderpopular-o-grande-desafio-do-novo-seculo.html>. Acesso em: 06 mar. 2016.

MIANI, Rozinaldo Antonio. Os pressupostos teóricos da comunicação comunitária e sua condição de alternativa política ao monopólio midiático. Intexto, Porto Alegre, UFRGS, v.02, n.25, p. 221-233, dez. 2011. Disponível em: <http://www.seer.ufrgs.br/ intexto/article/viewFile/16547/14492>. Acesso em: 08 fev. 2016.

MIANI, Rozinaldo Antonio; FELÍCIO, Camila Felício Rodrigues. O planejamento participativo no contexto da comunicação popular e comunitária. Anais. Congresso Brasileiro de Ciências da Comunicação - Intercom, 32., 2009, Curitiba: Intercom, 2009.

MINISTÉRIO DAS COMUNICAÇÕES. Rádio comunitária: processos autorizados. Brasília, 2012. Disponível em: <http://www.mc.gov.br/editais-e-avisos/doc_ download/553-entidades-autorizadas>. Acesso em: 10 nov. 2012.

OLIVEIRA JÚNIOR, José Amorim de. A influência da ação coletiva das associações no poder e no desenvolvimento sociopolítico local, em Tocqueville. Santa Cruz do Sul, RS, 2006. Disponível em: <http://online.unisc.br/seer/index.php/barbaroi/ article/ viewFile/815/599>. Acesso em: 06 mar. 2016. 
PAIVA, Raquel. O espírito comum: comunidade, mídia e globalismo. Petrópolis, RJ: Vozes, 1998.

PERUZZO, Cicília Maria Krohling. Comunicação nos movimentos populares: a participação na construção da cidadania. Petrópolis, RJ: Vozes, 1998.

I FÓRUM ESTADUAL DE RÁDIOS COMUNITÁRIAS. Folder de programação, 2003. 
AÇÃO MIDIÁTICA, n.13. Jan./Jun. 2017. Curitiba. PPGCOM-UFPR. ISSN 2238-0701

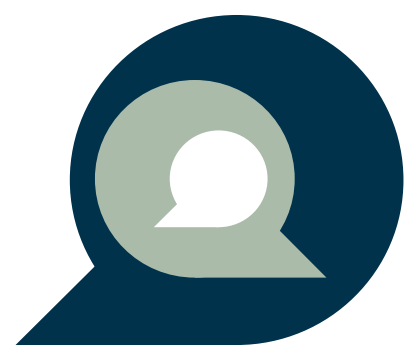

